\title{
Heat savings and heat generation technologies: Modelling of residential investment behaviour with local health costs
}

\author{
Zvingilaite, Erika; Klinge Jacobsen, Henrik
}

Published in:
Energy Policy

Link to article, DOI:

10.1016/j.enpol.2014.11.032

Publication date:

2015

Document Version

Peer reviewed version

Link back to DTU Orbit

Citation (APA):

Zvingilaite, E., \& Klinge Jacobsen, H. (2015). Heat savings and heat generation technologies: Modelling of residential investment behaviour with local health costs. Energy Policy, 77, 31-45.

https://doi.org/10.1016/j.enpol.2014.11.032

\section{General rights}

Copyright and moral rights for the publications made accessible in the public portal are retained by the authors and/or other copyright owners and it is a condition of accessing publications that users recognise and abide by the legal requirements associated with these rights.

- Users may download and print one copy of any publication from the public portal for the purpose of private study or research.

- You may not further distribute the material or use it for any profit-making activity or commercial gain

- You may freely distribute the URL identifying the publication in the public portal

If you believe that this document breaches copyright please contact us providing details, and we will remove access to the work immediately and investigate your claim 


\title{
Heat savings and heat generation technologies:
}

\section{Modelling of residential investment behaviour with local health costs}

\author{
Erika Zvingilaite ${ }^{\mathrm{a}}$ \& Henrik Klinge Jacobsen ${ }^{\mathrm{a}}$ \\ Technical University of Denmark, DTU Management Engineering, \\ Systems Analysis Division, P.O. Box 49, DK-4000 Roskilde, Denmark \\ Preprint: Energy Policy 77, p. 31-45., 2015
}

\begin{abstract}
The trade off between investing in energy savings and investing in individual heating technologies with high investment and low variable costs in single family houses has been modelled for a number of building and consumer categories in Denmark. The households have an option to combine their primary heating source with secondary heating e.g. woodstove. We address increased indoor air pollution with fine particles, which are potentially harmful to human health, when using a woodstove. We integrate health cost due to use of woodstoves as secondary heating source into household optimisation of heating expenditures. We investigate whether the monetary value of the possible health damage has an effect on the optimal consumer choice of a heating technology and heat saving investment. The results show that due to a combination of low costs of primary fuel and low environmental performance of woodstoves today, included health costs lead to decreased use of secondary heating. Overall the interdependence of heat generation technology- and heat saving-choice is significant. The total optimal level of heat savings for private consumers decrease by $66 \%$ when all have the option to shift to the technology with lowest variable costs.
\end{abstract}

Keywords: Energy savings; externalities; modelling; residential heating; rebound

\section{INTRODUCTION}

Three quarters of final energy, supplied to the EU households is consumed for space heating (ODYSSEE, 2009). A considerable share of this energy goes to cover heat losses that can be eliminated by employing well known techniques, such as improving thermal insulation of building envelope and replacing windows with more efficient ones i.e. energy refurbishments. It has been estimated, that it is technically possible to reduce heat demand by $40 \%$ by 2030 by refurbishing existing buildings in the EU-27 countries (European Commission, 2011). There is however a large gap between these technical options and the actual investments made. Understanding the investment behaviour and existing incentives are crucial when addressing the optimal investments into energy refurbishments and the policy measures that can affect the behaviour of, for instance, homeowners.

About 20\% of primary energy in Denmark is consumed for space heating in buildings (DEA, 2011). For households the heating share is 70 to $80 \%$ of final energy consumed in the household. Technical heat saving potential of energy refurbishments in the Danish building stock is estimated at 75-80\% by 2050 (Tommerup and Svendsen, 2006). This illustrates the importance of providing cost reflecting price signals and removing distorting barriers for private investments in energy refurbishments.

When a new building is constructed, decisions determining the energy efficiency of the building, and at the same time heat source and heating technology are made. These are long-term investment decisions that define thermal comfort level, energy demand for heating, fuel dependency and heating costs, as well as environmental impacts of the building for at least a couple of decades. These choices can only be changed in the long term in connection

a Tel: +45 46775109 E-mail: jhja@dtu.dk 
with a larger renovation of the building (Siller et al., 2007). Thus, choices, made during construction/renovation of buildings are significant for overall energy consumption in a country or region.

The IPCC report on Mitigation of Climate Change (IPCC, 2007) stresses the importance of integrated design buildings, engineering systems and generation technologies should operate effectively together in order to utilise energy in the most efficient way possible. Decisions, regarding energy refurbishment and choice of heat generation technologies are inter-dependent. Several studies (Tommerup and Svendsen, 2006, Amstalden et al., 2007, Gaterell and McEvoy, 2005) have shown that the price of heat, delivered to a building is a decisive factor for the economic effectiveness of energy refurbishments of buildings. Clearly, the price depends on the cost and efficiency of heat generation technology, fuel used as well as energy taxation. Contrary to heat consumers, connected to a district heating system, homeowners with individual heating technologies have greater flexibility to decide upon the cost of heat by choosing technology and fuel. The challenge for these consumers is to find an optimal trade-off between investments into energy refurbishments to achieve heat savings and heat generation costs. Such a decision depends clearly on the cost-characteristics of different alternatives - investment and operation costs and fuel prices. Private decisions about savings investment are often assumed to include technology (investment and operation) costs, avoided energy expenditures, but not heath costs associated with local heat generation. Environmental externalities and co-benefits of heat generation technologies and heat savings are described in several studies (Jakob, 2006, Banfi et al., 2008, Clinch and Healy, 2001). However, externalities are not included in decisions by private homeowners except for the emission taxes included in fuel prices. While, in fact, the residential heating sector is one of the main sources of local air pollution and part of the pollution is directly affecting health of the residents. For example, high wood consumption in heat boilers and particularly in wood stoves and fireplaces by the Danish households accounts for almost $70 \%$ of national emissions of fine particles $\mathrm{PM}_{2.5}$ (Nielsen et al., 2010). These emissions increase air pollution level in residential areas and cause health damage locally and indoor (Olesen et al., 2010). Consequently, part of these health related costs from secondary heating technologies should be considered internal for the household decisions.

Consequently, in this paper we investigate and discuss two research questions:

- How can inclusion of local health costs change the investment decisions in the residential heating sector?

- How significant is interdependency of heat saving measures and individual heat generation technologies?

We identify the main characteristics of individual heating - different consumer groups and their heat demand, primary and secondary heat generation technologies, fuels and their prices, including levies and energy taxes. Furthermore we analyse heat saving potentials and costs in the analysed buildings. We construct an optimisation model for the private investment decisions by households and analyse scenarios with different investment flexibility. Finally we assess the rebound effect of heat consumption, as a result of decreased variable heating cost per square meter of heated area.

\section{SAVING OPTIONS, HEAT TECHNOLOGY CHOICE AND EXTERNALITIES}

Demand for heating is an important part of energy demand in countries with cold climate such as Denmark, and depends on a number of parameters of which some are individual and others are set by the regulatory and planning environment. Property tax schemes affect dwelling size and urban planning affect types of dwellings and heating sources. Building codes also regulate in detail the materials and heat loss of dwellings. Individuals demand indoor thermal comfort in their dwellings and primary energy for heating is thereby not directly providing use (or utility) to households.

This paper models the private integrated choice of heating technology and investments in energy savings. We start by discussing consumer control of the elements in the energy chain from comfort level to the primary fuel use.

Individual required thermal comfort level basically depends on consumer's:

- income 
- $\quad$ price of heat

- habits/preferences

With rising income individuals increase their demand for heating comfort by increasing indoor temperature and heating more rooms a larger fraction of the year. Income elasticity's are generally found to be considerably less than 1 for heating characterising it as a basic good.

An increase in the price of heating comfort reduce the demand by making people more aware of avoiding excess heating in areas not used and directly affect the indoor temperature they set. Empirical estimates for price elasticity's are found in a broad range between -0.1 and -1 .

Habits based on historical trends and social organisation of family life etc. affects the demand, which is seen especially when comparing across countries. The demand for heating comfort is only the first step in determining the energy needed for heating purposes. The comfort level is a result of useful, energy delivered to a dwelling and energy efficiency of the building envelope. A homeowner is directly in control of the chosen comfort level and the investments that could improve energy performance of the building. Energy saving investments are undertaken as long as their costs per saved energy are below the costs of the useful energy delivered for heating the house. The home owner on the other hand only controls some of the parameters that determine costs of the supplied heat. The costs of each type of fuel including electricity and district heating are not controlled by a consumer. Total energy consumption for supplied heating comfort is determined by the efficiency of the heating system in a building, local conversion efficiency at the building (e.g. individual heat technologies or a district heating connection), efficiency of energy supply system (district heat, electricity and gas networks), central heat and electricity generation efficiency which determines the primary fuel input. Of these, building heating systems are mostly controlled by the homeowners. The local heat (generation) technologies are sometimes controlled (when there are no legal restrictions) by the owner, but there are often high investment costs and long lifetime of such equipment, which limits the flexibility for the consumer.

We focus our analyses to the specific situation set by the Danish regulations, building codes and characteristics of the building stock. The existing building stock determine a major part of energy consumption for space heating for a reasonable time horizon as the new buildings have low energy consumption and are only added gradually. This effect of gradually improving heating efficiency with new vintages of buildings is for example illustrated in a model for Denmark (Klinge Jacobsen, 2000). Due to the restrictions on shifting away from district heating we concentrate our investment modelling on the individual heating technologies excluding thereby the share of dwellings in Denmark with district heating. For existing dwellings the choice of comfort level is free, but the heat saving investments are characterised by high costs except when buildings are undergoing renovation anyway. Therefore saving investment have to be modelled with different costs in these two situations. The choice of heating technology can be considered free for residential buildings that are not situated within district heating areas. In general, economic and technical lifetime of individual heat generation technologies, such as electric heating, and to some extent gas oil-, biomass- natural gas-boilers and similar technologies is limited to 15 to 20 years.

\section{Externalities}

The energy sector causes global and local environmental impacts. Global warming effects due to emissions of greenhouse gasses from fossil fuel combustion are of major international concern. At the same time regional environmental problems and local damage of human health due to pollution with $\mathrm{SO}_{2}, \mathrm{NO}_{\mathrm{x}}, \mathrm{PM}_{2.5}$ etc. are also seriously affecting health. For individuals the local health costs are more important than global effects when investing in heat savings and choosing the heating technology.

For the residential sector internalisation of externalities are represented through the taxes imposed on their energy use. This mainly covers the effects associated with $\mathrm{CO}_{2}$ emissions, whereas the other more local emission effects are not accounted for. As the local effects to some extent are controlled by individuals through their choice of heating technology and fuels these costs should enter the decision process of the optimising individual.

In Denmark $\mathrm{CO}_{2}$ emissions directly associated with consumption by households have decreased by around $45 \%$ during the last 20 years (DEA, 2011). This is especially a result of reduced oil consumption in the residential 
heating sector caused by savings and substitution, where oil has been replaced by district heating, natural gas and also a considerable growth in the use of wood and wood pellets. Combustion of wood and wood pellets for the domestic heating has increased nearly four times during that period and continues to grow. As a result, households have become significant contributors to the release of local air pollutants, particularly fine particles $-\mathrm{PM}_{2.5}$. Consequently, almost $70 \%$ of national fine particle emissions come from residential wood combustion in boilers, stoves and fireplaces (Nielsen et al., 2010). This illustrates the importance of controlling this particular emission source, and we therefore investigate whether private optimisation should theoretically limit the expansion of such technologies because of their health costs.

A number of studies (Pope and Dockery, 2006) have shown a clear correlation between particle pollution and adverse health effects. Release of particles from domestic wood combustion in dense residential neighbourhoods cause pollution concentrations that are comparable to air pollution in urban areas with heavy traffic (Olesen et al., 2010). Pollutants from a woodstove or an individual boiler are released at a low altitude $(\sim 6 \mathrm{~m})$ and in highly populated areas - thus possibilities for pollutant dispersion and dilution are poor and population exposure to harmful particles is high. Domestic wood combustion is characterised by high particle emission rates. The least polluting technology - a modern wood pellet boiler - emits up to 30 times more $\mathrm{PM}_{2.5}$ than a central biomass plant. Release from a modern wood stove is around ten times higher than that of the wood pellet boiler and several hundred times higher than for a central wood-based plant (Olesen et al., 2010). Furthermore the Danish study WOODUSE (WOODUSE, 2009) has shown that wood stove use can contribute considerably to indoor air pollution - especially during the lighting of a cold stove and due to a poor draught in the chimney (Olesen et al., 2010). The households are both - personally involved in causing negative environmental effects and are directly experiencing these effects (Petersen, 2008). Thus, health related effects from domestic wood combustion should be considered internal for the mentioned households and should affect their investment behaviour. We concentrate our analysis on health costs of particle pollution from woodstove use only.

\section{THE MODEL AND SCENARIOS}

The model illustrates decision making in the residential sector when investments in different heat generation technologies and heat saving measures are considered and when health damage costs of particle emissions from woodstoves are included in the consumer's choice of heating. Investments in heat savings reduce the amount of heat production, needed for covering heat losses through building envelope and ensuring desired indoor temperature. The benefits of heat savings are reflected in reduced fuel consumption and fuel costs and to some extent lower investments in heating technologies. If woodstove use is replaced, heat saving benefits also include reduced air pollution and related health damage.

We apply an optimisation modelling approach for the decisions by different groups of residential consumers with individual heating technologies. This choice implies the assumption, that the consumers behave rationally and they only derive utility from the heating services. In reality there are other benefits from different heating technologies such as the joy of watching the wood stove burning.

The objective function minimise private costs for covering annual demand for thermal comfort and hot water. It includes investments into heat generation technologies ( $\left.I C_{C G, H G}\right)$; operation and maintenance cost ( $\left.O M C_{C G, H G}\right)$; fuel cost $\left(F C_{C G, H G}\right)$; health costs of air pollution $\left(H C_{C G, H G}\right)$ and heat saving investments $\left(I C_{C G, E L M}\right)$ :

$$
\min \sum_{C G} \sum_{H G}\left(I C_{C G, H G}+O M C_{C G, H G}+F C_{C G, H G}+H C_{C G, H G}\right)+\sum_{C G} \sum_{E L M} I C_{C G, E L M}
$$

The subscripts mean the following:

$C G$ - consumer group by building type and age, exiting heating technology, owner-occupied or rented, with or without a woodstove and with or without a cellar;

$H G$ - heat generation technology, used in a scenario (including woodstoves);

$E L M$ - implemented energy efficiency improvement measure. 
The objective function minimises annual heating costs (includes also heat saving investments) - for all consumer groups. Heat generation and implementation of heat savings are independent in each consumer group, as they do not compete for the same limited resource and all constraints are defined for every consumer group. This means each category of dwellings (consumers) is treated as a private representative entity minimising the costs independently from all other categories. Therefore, the result of overall optimisation reflects optimal heat generation and heat saving solutions for each consumer group separately.

The annual cost of covering heating demand is minimised in the model. Hence annualised investment costs are included in the objective function for both heat generation technologies and heat saving measures. The investment costs are annualised based on their technical lifetime:

$I C^{\text {annual }}$ - annualised cost of investment;

$$
I C^{\text {annual }}=I C \cdot \frac{r}{\left(1-(1+r)^{\left.-L T_{T}\right)}\right.}
$$

IC - investment cost of a technology or heat saving measure;

$L T_{T}$ - technical lifetime of an investment;

$r$ - private discount rate

Heat generation technologies have shorter lifetime than most heat saving measures. When comparing costs of heat savings with costs of e.g. boilers the underlying assumption is that investments in heating technologies can be identically repeated. This means that the higher risk, related with long term investments, is not accounted for in the described optimisation.

When reinvesting or investing into new technologies, the building heating system (radiators) and other ancillary installations (e.g. accumulator tank or ground heat exchangers) are also replaced. Ancillary investments $\left(I C_{2}\right)$ have a longer lifetime than heat generation technologies $\left(I C_{1}\right)$. Hence the total investment costs of heating technologies consist of at least two parts with different technical lifetime. The annualised capital costs, included in the model, are calculated by simple addition of investments, annualised by using respective lifetime ( $L T_{1}$ and $\left.L T_{2}\right)$ :

$$
I C_{\text {total }}^{\text {annual }}=I C_{1} \cdot \frac{r}{\left(1-(1+r)^{-L T_{1}}\right)}+I C_{2} \cdot \frac{r}{\left(1-(1+r)^{-L T_{2}}\right)}
$$

Simply adding the annuities for the two parts of a heat supply technology with different lifetimes clearly includes an assumption that an additional investment $I C_{1}$ can be made for the remaining lifetime of $I C_{2}$. The annual productivity/efficiency of the investment $I C_{2}$ is assumed identical for the entire lifetime $L T_{2}$. No technology investment costs are included in the expenditures by consumers, renting their dwellings. Technology is assumed to be installed by a landlord. Whereas heat saving investments, are considered to be a free choice by the renters. For rented buildings an 8 year investment horizon is considered in the calculations. Hence the investments are annualised using lifetime of 8 years. This considerably reduce the profitability of heat saving investment for renting categories.

The yearly health costs of air pollution ( $\mathrm{HC}_{\mathrm{CG}, H G}$ ) include damage of consumer health due to indoor emissions of fine particles $\left(\mathrm{PM}_{2.5}\right)$ from woodstoves. Clearly, the indoor air pollution depends on the consumer behaviour, when using woodstove, however this variation is not analysed in this paper. Internal health costs due to own air pollution from heat boilers are considered to be insignificant for the residents.

Heat demand includes energy needed for both domestic hot water and for ensuring comfortable indoor temperature. In the model this demand is a result of the total heated area $A_{C G}(\mathrm{~m} 2)$ of each building group and the current specific heat demand $S D H_{C G}\left(\mathrm{kWh} / \mathrm{m}^{2}\right)$ of the buildings. The initial demand is calculated exogenously as:

$$
D H_{G}=A_{C G} \cdot S D H_{C G}
$$

The demand of each consumer group can be covered by reducing heat loss from buildings by investing in energy efficiency improvements of building elements and installing ventilation with heat recovery, when buildings are 
renovated. The remaining heat demand for preparation of domestic hot water and for covering the (remaining) heat losses can be supplied by heat generation in primary and a single secondary heating technology woodstoves. This is chosen as the most common technology and causing significant impact on health. These relations are expressed by the heat balance equation in the model:

$D H_{C G}=\sum_{H G} H P_{C G, H G} \cdot(1-H L O S S)+\sum_{H G 2} H P 2_{C G, H G 2}+\sum_{E L M} H S_{C G, E L M}$

Here:

$D H_{C G}$ - annual heat demand by consumer group, kWh;

$H P_{C G, H G}-$ yearly heat production by technology in each consumer group, $\mathrm{kWh}$;

$H P 2_{C G, H G 2}$ - yearly heat production by woodstoves in different consumer groups (secondary heating), kWh;

$H S_{C G, H G}$ - yearly heat savings, achieved by investing in different saving measures, kWh;

HLOSS - heat losses in engineering heating and hot water system, which are not utilised for heating, kWh.

We assume a woodstove only serves as secondary technology and cannot cover hot water preparation. Therefore heat generation by woodstoves is modelled with limits:

$H P 2_{C G, H G 2} \leq S E C H_{H G 2} \cdot\left(D H_{C G}-H S_{C G}\right)$

Here $S E C H_{H G 2}$ is a share of the heat demand in a building that can be covered by using a woodstove. Based on statistics of yearly wood use per woodstove and it is assumed that woodstoves can cover maximum $30 \%$ of the heating demand in buildings.

Heat savings achieved by investing in insulation of walls and other energy efficiency improvements are calculated as follows:

Here:

$$
H S_{C G}=\sum_{E L M} H S P_{E L M} \cdot H S A F_{C G, E L M}
$$

$H S P_{E L M}$ - heat savings potential of an implemented heat saving measure, $\mathrm{kWh} / \mathrm{m}^{2}$ :

$H S A F_{C G, E L M}$ - heated floor area, which corresponds to a share of buildings, with implemented energy efficiency improvements by heat saving measure/element (ELM), $\mathrm{m}^{2}$.

In the situation where a building undergoes a major renovation and additional savings costs are low, then $H S A F_{C G, E L M}$ is limited to a share of buildings that are expected to go through a larger refurbishment $-R E N_{C G}$.

$$
H S A F_{C G, E L M} \leq R E N_{C G} \cdot A_{C G}
$$

We calculate 3 different scenarios where we analyse different cases (Table 1).

Table 1 Calculated scenarios and cases

\begin{tabular}{|l|l|l|l|}
\hline $\begin{array}{c}2011 \text { with existing } \\
\text { technologies }\end{array}$ & $\begin{array}{c}2030 \text { with reinvestment in the } \\
\text { same technologies as existing }\end{array}$ & $\begin{array}{c}\text { 2030 free choice } \\
\text { of technologies }\end{array}$ & \multicolumn{1}{|c|}{ Description } \\
\hline REF & REINVEST_REF & INVEST_REF & $\begin{array}{l}\text { Reference case - heat saving options } \\
\text { or health costs are not included }\end{array}$ \\
\hline BASE & REINVEST & INVEST & Heat saving options are included \\
\hline REF_EXT & REINVEST_EXT & INVEST_EXT & $\begin{array}{l}\text { Health costs are included } \\
\text { are included }\end{array}$ \\
\hline BASE_EXT & \multicolumn{2}{|l}{ havings and health costs } \\
\hline
\end{tabular}


Comparing between different scenarios and cases we can illustrate the effect of combining general dwelling renovation with heat savings investments and investments in heat generation technology.

\section{DATA}

The analysis focuses on currently existing dwellings in Denmark that do not have access to a district heating network. The model use heat demand in the existing buildings and currently operating individual heating technologies.

The specific heat demand $\left(S D H_{C G}, \mathrm{kWh} / \mathrm{m}^{2}\right)$ is based on data from (Rambøll Denmark, 2008) where heat demand is calculated for year 2006. We do not project heat demand for year 2030 - instead, we analyse the same existing buildings and their heat demand, based on 2006 data, in another situation i.e. with fuel prices, and technical and cost characteristics of heating technologies which are projected to 2030.

The consumer groups included in the model (Table 2) represent different building categories. Buildings in each group are represented by total heated floor area $\left(\mathrm{m}^{2}\right)$. The data is extracted from Heat Atlas - a GIS database, which includes data on building age and purpose as well as heat source in the Danish buildings (Möller, 2008). The analysis is limited to detached and non-detached single family houses and farmhouses. The buildings are further grouped by their age (time of construction) and by individual heating technology. The Heat Atlas also includes information on secondary heating technology - and we use the information for woodstoves. Finally residential heat consumers are grouped by - owner-occupied or rented; and for heat saving calculations buildings are further divided in two groups - with and without a cellar. Consequently, the analysis includes 1008 categories of consumers.

Table 2 Categories for consumer groups

\begin{tabular}{|l|l|}
\hline Building purpose & Farmhouses; detached single family houses; non-detached single family houses \\
\hline Building construction period & $<1930 ; 1931-1950 ; 1951-1960 ; 1961-1972 ; 1973-1978 ; 1979-1998 ; 1999-2003$ \\
\hline Primary heating technology & $\begin{array}{l}\text { Biomass (wood pellet) boilers; Electric heating; Heat pumps air-water; Heat pumps } \\
\text { ground-water; Natural gas boilers; Oil boilers }\end{array}$ \\
\hline Secondary heating with woodstoves & No secondary heating; Woodstoves \\
\hline Ownership/occupant type & Owner-occupied; Rented \\
\hline Cellar & Buildings with cellar; Buildings without cellar \\
\hline
\end{tabular}

Figure 1 illustrates the share of different buildings by ownership (to the left) and the diffusion of woodstoves within different building types in the model. Non-detached single family houses have the highest share of rented houses - almost 60\%. Woodstoves are mostly installed in detached single family houses and farmhouses.
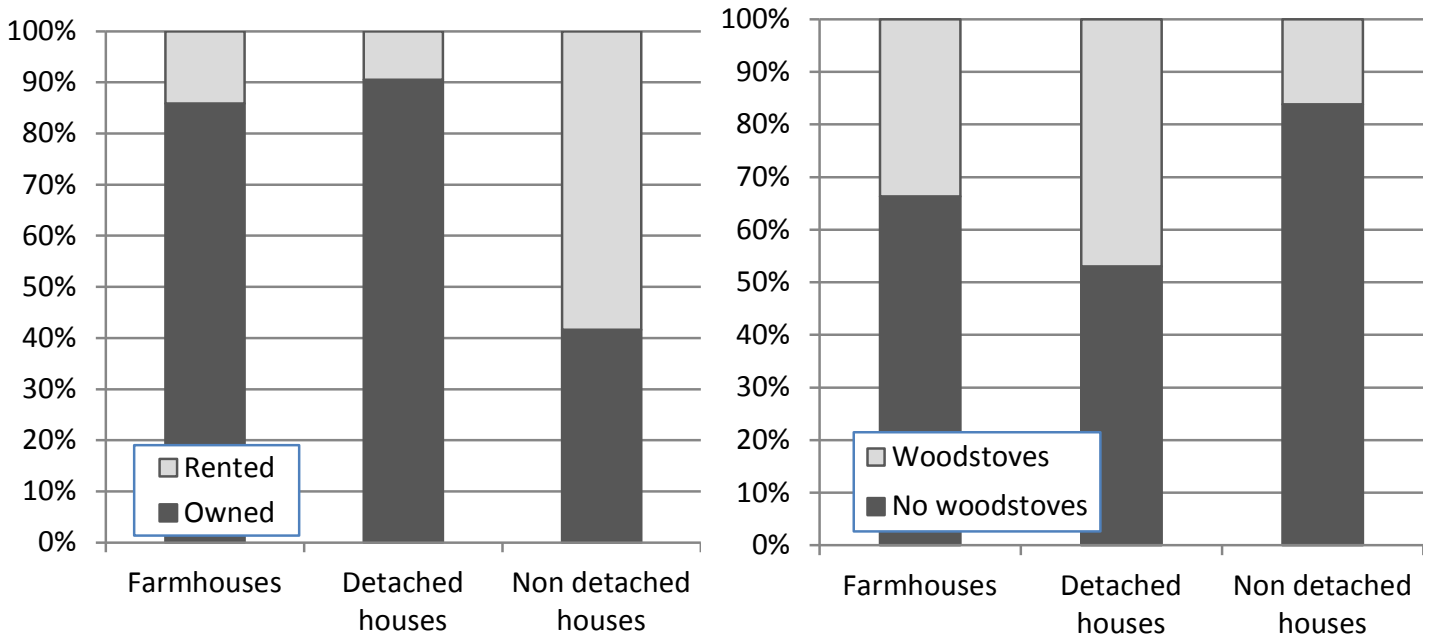

Figure 1 Distribution of the analysed single family houses by ownership (to the left) and secondary heating source (to the right)

The total heat demand in the three building types in the model reaches 16.5 TWh (Figure 2) and amounts to around one third of current heat consumption in all buildings in Denmark. 


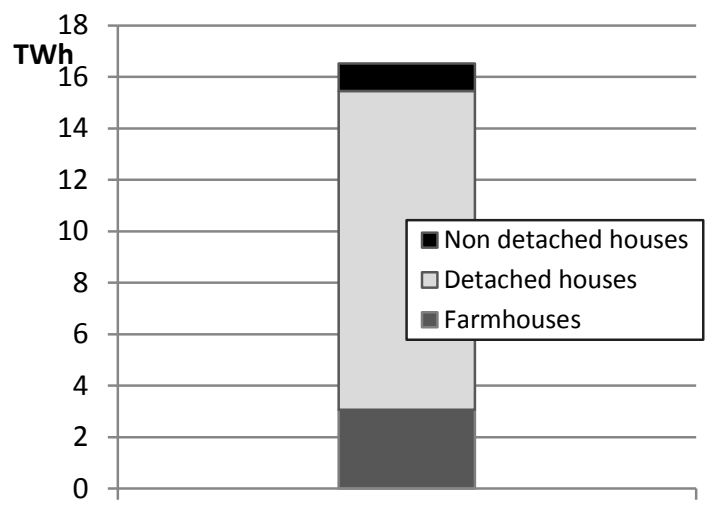

Figure 2 Total heat demand of analysed buildings

The buildings with individual heat generation, included in the analysis, are dominated by detached single family houses. Heat demand in these houses amounts to $75 \%$ of the total heat demand covered by the model.

\section{Heat Savings}

Five heat savings measures are included in the calculations - additional insulation of walls, roof and floor, more energy efficient windows and mechanical ventilation with heat recovery. Heat savings potential of different saving measures depends on the heat loss reduction through the improved building elements and by reduced heat losses due to ventilation. The total heat savings potential included in the model is $9.2 \mathrm{TWh}$ and reaches $56 \%$ of the total heat demand in the calculations. Such heat savings correspond to $18 \%$ of heat consumption in all Danish buildings today.

The costs of improving energy efficiency of the building envelope for different building types are based on Wittchen (2004), Kragh and Wittchen (2010) and Tommerup (2010). The investment costs per m2 of heated floor area and the lifetime of heat saving measures in the model are presented in Table 3.

Table 3 Heat saving costs and assumed lifetime

\begin{tabular}{|c|c|c|c|c|}
\hline \multirow{2}{*}{ Heat saving measure } & Insulation after savings & Investment cost $2011^{\text {a }}$ & Investment cost $2030^{a}$ & Lifetime \\
\hline & $\mathrm{mm}$ & $\mathrm{EUR} / \mathrm{m}_{\text {floor }}^{2}$ & $\mathrm{EUR} / \mathrm{m}_{\text {floor }}^{2}$ & Years \\
\hline Wall & 300 & $187.9-229.0$ & $171.3-208.7$ & 40 \\
\hline Floor & $100 / 150$ & $35.2 / 48.1$ & $32.1-43.9$ & 40 \\
\hline Roof & 400 & $20.1-55.0$ & $18.4-50.2$ & 40 \\
\hline Window & $U_{\text {value }}=1 \mathrm{~W} / \mathrm{m}^{2} \mathrm{~K}$ & 27.7 & 25.2 & 20 \\
\hline Ventilation with heat recuperation & - & 67.1 & 61.2 & \\
\hline
\end{tabular}

a the variation is due to different additional insulation thickness needed and different element-to-heated floor area ratio for different buildings

The costs are additional costs for efficiency improvements and do not include the general building refurbishment expenses.

\section{Health costs}

In this analysis we focus on emissions of local pollutants that can cause negative health effects, namely, emissions of fine particulates $\left(\mathrm{PM}_{2.5}\right)$. In the model potential negative environmental and health effects of woodstove use are incorporated in heating decisions by consumers. The average external health cost of $28.1 \mathrm{EUR} / \mathrm{kg}$ for particle emissions from residential sector in Denmark is used as internal health cost of $\mathrm{PM}_{2.5}$ for private consumers and is the same for different locations - urban and rural (Brandt et al., 2011). This is an assumption, which can underestimate the negative effects that woodstove users experience, in the case of high indoor air pollution with particles. On the other hand, in the case of a well controlled and low polluting wood-burning practice the cost can be overestimated. Nonetheless, on a yearly basis, the health cost of particles used for the calculations is lower than the woodstove tax, proposed by the Danish Ecological Council (2012).

Emissions of other local pollutants (e.g. $\mathrm{NO}_{x}, \mathrm{SO}_{2}$ ) as well as emissions from other residential heat generation technologies (e.g. oil boilers) are not considered in the private economic optimisation. 


\section{Heat generation technologies}

Individual heating technologies generate heat at different costs and have different emission rates. In the scenarios two types of individual heating technologies have been included - the technologies, that cover heat demand today and the new technologies, assumed to be available in 2030. Economic and technical characteristics of different technologies are presented in Table 4 and are mainly based on Rambøll Danmark (2008). The table includes cost data for technologies of $8.3 \mathrm{~kW}$, assumed to be installed in a single family house of $130 \mathrm{~m}^{2}$ with a yearly heat consumption of $15 \mathrm{MWh}$. The costs include the Danish value added tax, of 25\%.

Table 4 Characteristics of heating technologies

\begin{tabular}{|c|c|c|c|c|c|c|c|}
\hline \multicolumn{2}{|c|}{ TECHNOLOGY } & Lifetime & $\begin{array}{c}\text { Investment } \\
\text { cost }\end{array}$ & $\begin{array}{c}\text { Variable } \\
\text { share of } \\
\text { investment }\end{array}$ & O\&M cost & $\begin{array}{c}\text { Fuel } \\
\text { efficiency }\end{array}$ & $\begin{array}{c}\mathrm{PM}_{2.5} \\
\text { emissions }\end{array}$ \\
\hline & & YEARS & EUR/unit & $\%$ & EUR/unit/year & & $\mathrm{g} / \mathrm{GJ}$ \\
\hline \multirow[b]{2}{*}{$\begin{array}{l}\text { Ground source } \\
\text { heat pump }\end{array}$} & Heat pump & 15 & 10050 & 18 & \multirow[b]{2}{*}{100} & \multirow[b]{2}{*}{$2.9 / 3.3^{a}$} & \multirow[b]{2}{*}{-} \\
\hline & $\begin{array}{l}\text { Ground heat } \\
\text { exchanger }\end{array}$ & 40 & 6700 & 52 & & & \\
\hline \multicolumn{2}{|c|}{ Air-water heat pump } & 15 & 8375 & 52 & 75 & $2.4 / 2.8$ & - \\
\hline \multicolumn{2}{|c|}{ Wood pellet boiler } & 15 & 8375 & 6 & 282 & $0.78 / 1.0$ & $(32)^{b}$ \\
\hline \multicolumn{2}{|l|}{ Oil boiler } & 15 & 7500 & 6 & 230 & $0.85 / 1.0$ & $(5)$ \\
\hline \multicolumn{2}{|c|}{ Natural gas boiler } & 15 & 5000 & 6 & 105 & $0.88 / 1.02$ & $(0.1)$ \\
\hline \multicolumn{2}{|c|}{ Hydraulic heating system } & 40 & 6713 & 30 & 101 & $0.975^{\mathrm{c}}$ & - \\
\hline \multicolumn{2}{|c|}{ Electric water heater } & 20 & 1375 & 0 & 12 & 0.99 & - \\
\hline \multicolumn{2}{|c|}{ Electric heating } & 40 & 3356 & 30 & 50 & 1.0 & - \\
\hline \multicolumn{2}{|l|}{ Woodstove $^{\mathrm{d}}$} & 20 & 2813 & 0 & 42 & $0.5 / 0.7$ & $660 / 330^{a}$ \\
\hline \multicolumn{2}{|c|}{ Connection to natural gas supply } & 30 & 2013 & 0 & - & - & - \\
\hline \multicolumn{2}{|c|}{ Accumulator tank oil/heating } & 40 & 1678 & 0 & - & - & - \\
\hline
\end{tabular}

a existing technologies/new technologies in 2030

${ }^{b}$ emissions, presented in the brackets are not included in the model calculations

${ }^{\mathrm{c}}$ it is assumed that half of $5 \%$ heat losses are being transferred to heating of a building during winter period

${ }^{\mathrm{d}}$ Grønvald, 2007

e Dong Energy, 2012

Operation and maintenance costs, expressed in today's prices, are assumed to be the same for existing technologies and technologies installed in 2030. Fuel efficiency and emissions of fine particles are distinguished for current heating installations and future technologies. Only future technologies, installed in 2030, encounter investment costs.

In the model investment costs are distinguished between a fixed part and a variable part that depends on the necessary output capacity. In the model, fixed costs are expressed in EUR $/ \mathrm{m}^{2}$ of building heated area and variable costs in EUR/kW of installed capacity. The installed generation capacity depends on heat demand and assuming 2000 full load hours annually.

\section{Fuel prices}

Fuel prices are projected for 2030 (Table 5) based on current fuel and electricity prices for households combined with projections of underlying fuel costs from the Danish Energy Agency (2011). Current fuel and electricity consumer prices and taxes are presented in Figure 3. The prices include energy and environmental $\left(\mathrm{CO}_{2}\right.$ and $\mathrm{NO}_{\mathrm{x}}$ ) taxes as well as distribution (natural gas and electricity) and transportation fees. The prices and fees are based on the actual data from year 2011 (DERA, 2011; EOF, 2011; Sønderskovhjemmet, 2011; Sydjyskstoker, 2011). 


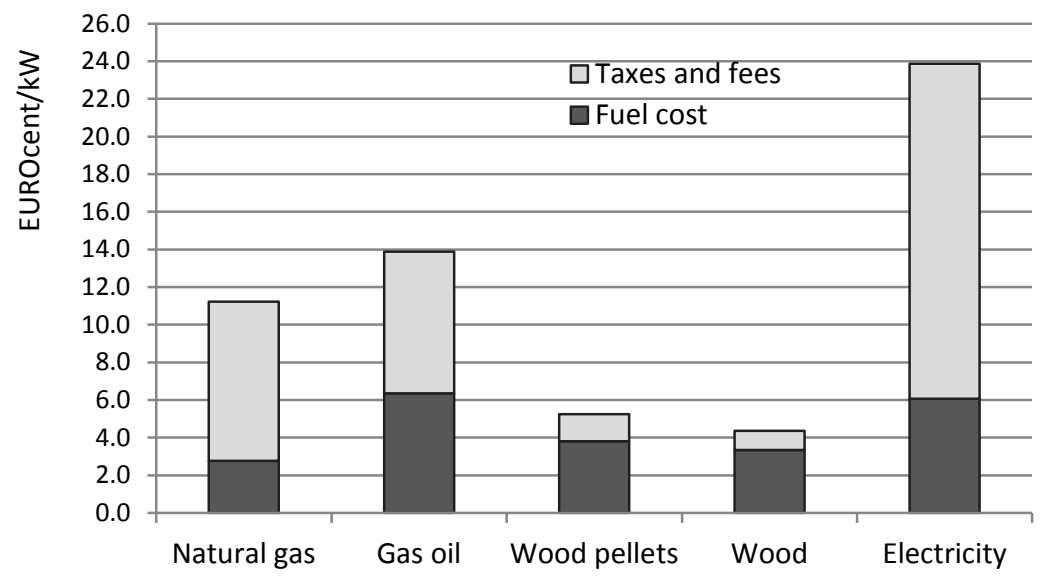

Figure 3 Fuel and electricity prices for private consumers in 2011

From Figure 3 it can be seen that a large share of the fossil fuel and electricity price for consumers is taxes and fees for distribution - for natural gas and electricity they reach $75 \%$ of the total price. At the same time taxes comprise only $25 \%$ of the final biomass price.

Table 5 includes fuel prices, used in the calculation in the two time periods in the analysis.

Table 5 Fuel prices for private consumers

\begin{tabular}{|l|c|c|c|c|c|}
\hline EURcent/kWh & Natural gas & Gas oil & Wood pellets & Wood & Electricity \\
\hline 2011 & 11.2 & 13.9 & 5.2 & 4.4 & 23.9 \\
\hline 2030 & 19.4 & 19.6 & 5.9 & 4.9 & 45.8 \\
\hline
\end{tabular}

\section{MARGINAL COST CURVES AND RESULTS}

Comparing heat saving options with heat generation technologies provide an overview of the cost characteristics included in the model. This is an important input to the model with Figure 4 and

Figure 5 illustrating that the cheap generation technologies only leave few energy saving options as attractive, namely windows and to a limited extent roof insulation. For comparison with heat saving costs, the figures include only the variable heating costs, which can be reduced by implementing heat savings. In 2011 no heat savings are cost-efficient if wood pellet boilers are used for heat generation, insulation of walls is not economically viable and ventilation with heat recuperation would only be installed in a few buildings with electric heating. Woodstove costs are here including health costs and are in the figure considerably higher than current kilowatt-hour cost of around $0.09 \mathrm{EUR} / \mathrm{kWh}$. In 2030 higher fuel prices but at the same time higher fuel efficiency of new technologies lead to still low wood pellet boiler and woodstove-based generation costs. Cost for implementing heat savings decrease by 2030. As a result insulation of walls is now cost-efficient for consumers with electric heating, windows are economically viable also where wood pellets are used for heat generation and roof insulation is cost efficient in combination with all heat generation technologies except wood pellet boiler. The cost curves are representing only the case where heating technology is fixed. 


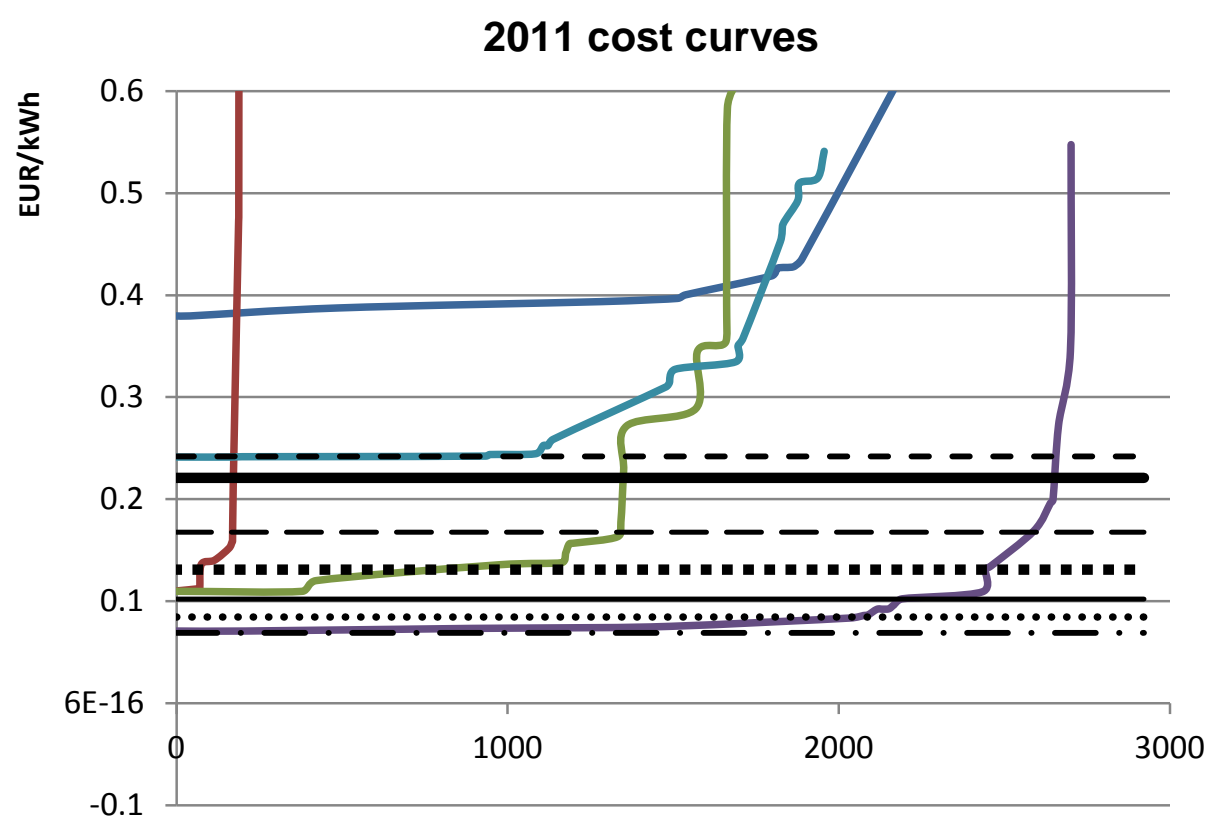

Heat saving potential, GWh

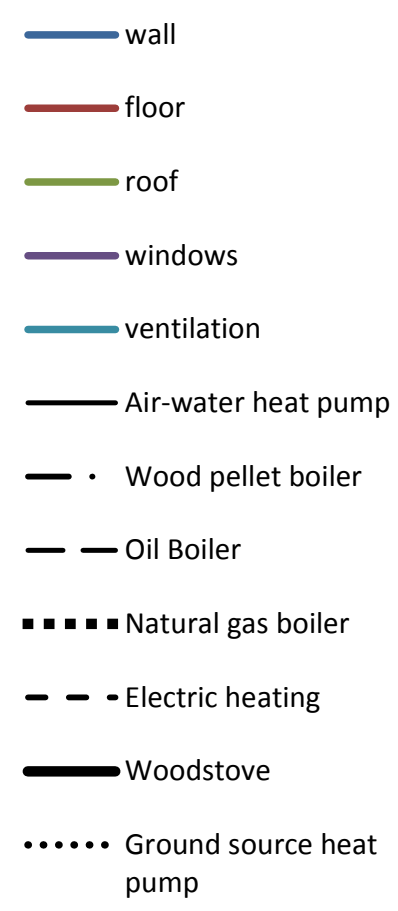

Figure 4 Heat saving and heat generation marginal cost curve for 2011.

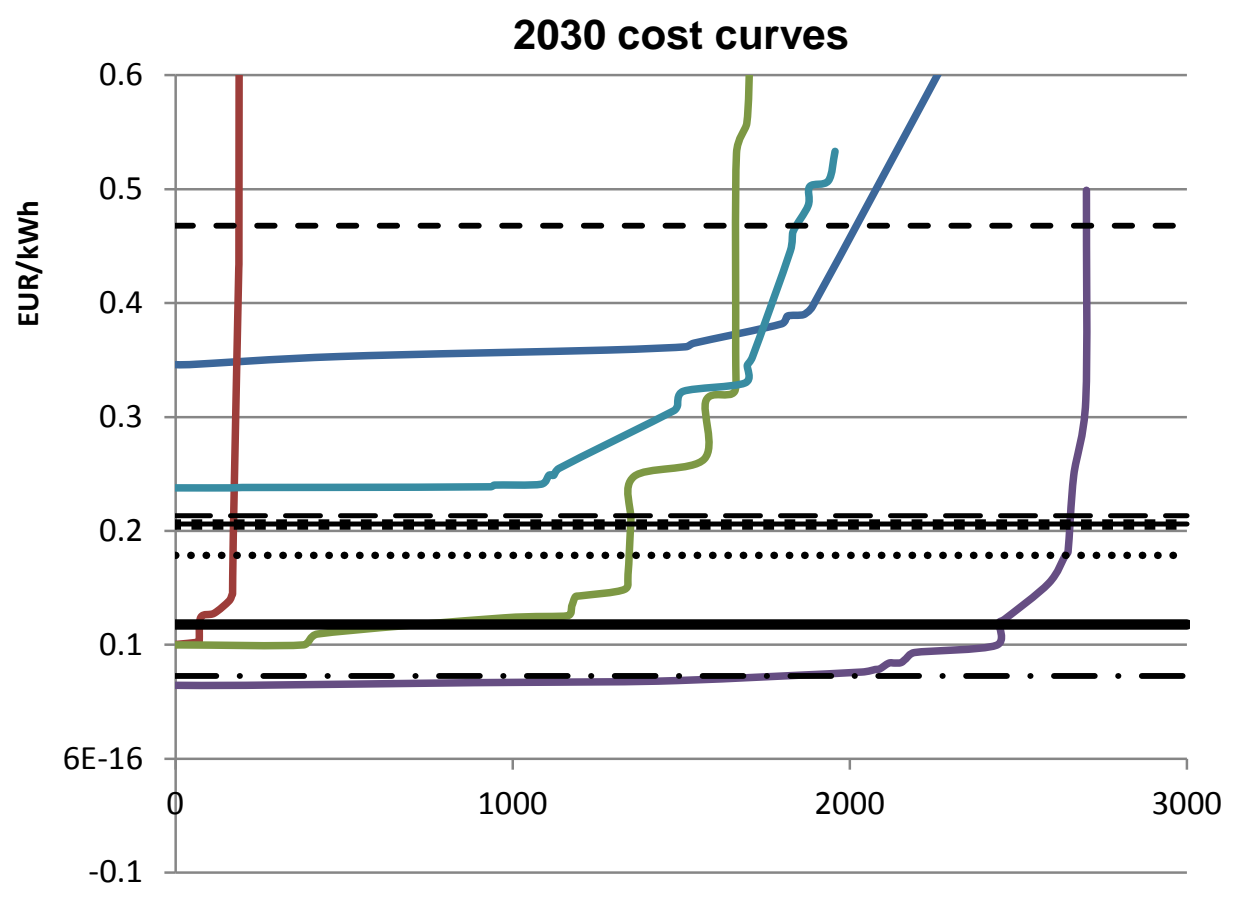

Heat saving potential, GWh

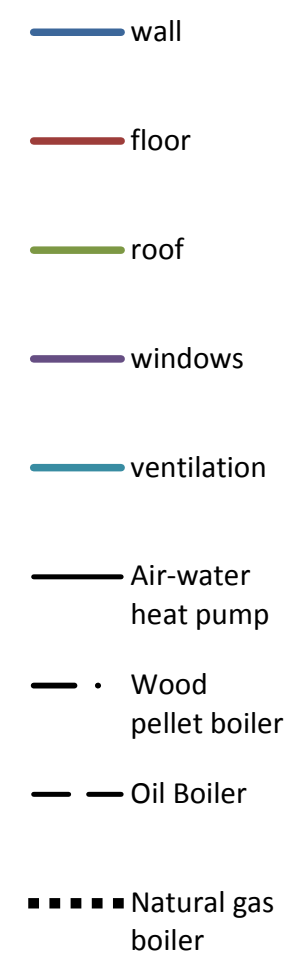

Natural gas

Figure 5 Heat saving and heat generation marginal cost curve for 2030 .

The costs in Figure 5 include incremental heat saving costs excluding renovation expenditures and heat generation costs include the variable part of investment costs, fuel costs and health costs for woodstoves. 

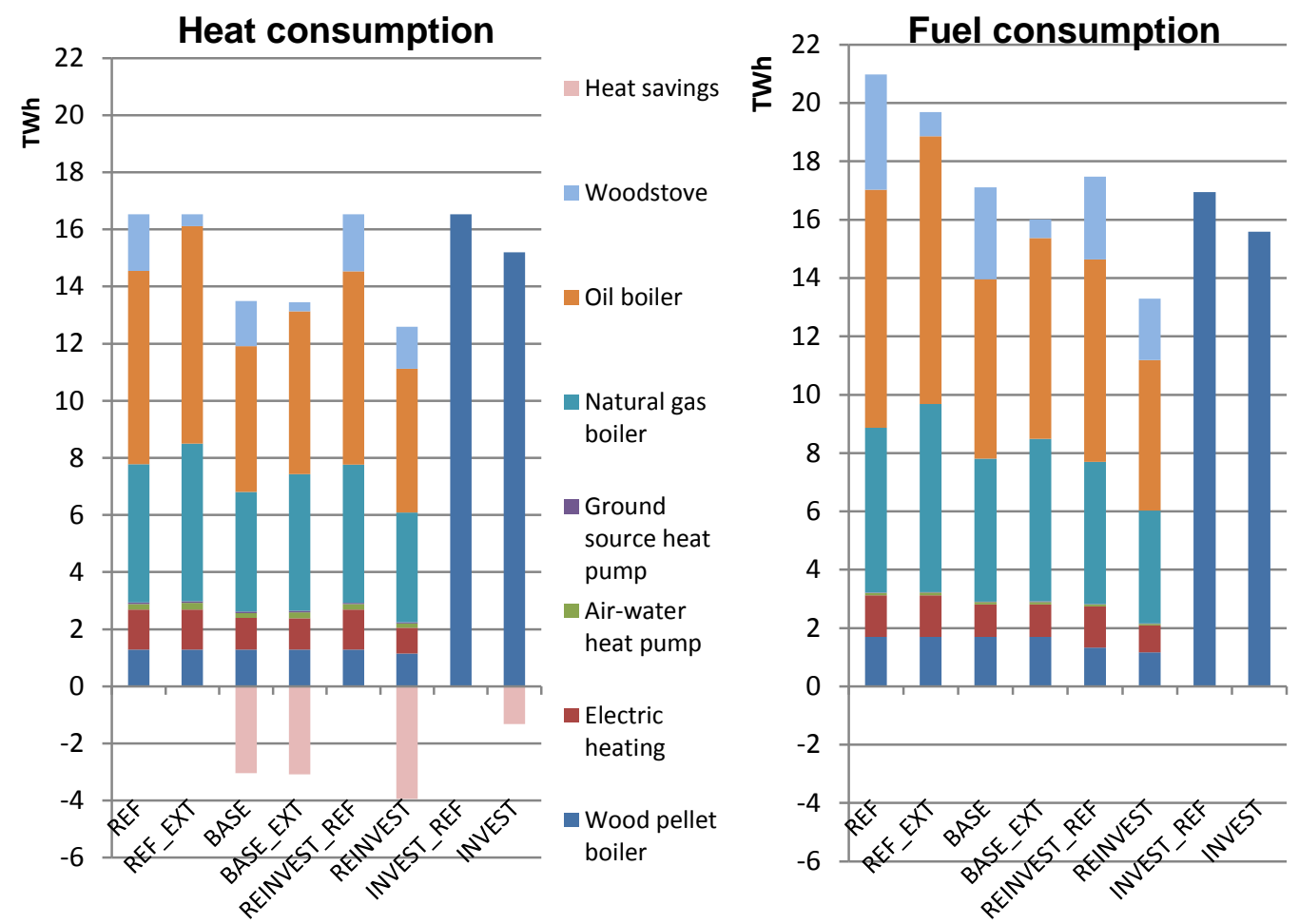

Figure 6 Heat consumption covered by different technologies (to the left) and fuel consumption for heat generation in different scenarios and cases (right)

Scenario REF in Figure 6 represents the optimised reference situation in the analyses. Around 12\% of total heat demand is covered by the secondary heating technology - woodstove. When health costs of woodstove use are included, utilisation of this technology decreases four times to 2.5 percent. Only consumers with electric heating still use woodstoves. Including heat savings in BASE and BASE_EXT cases for 2011 result in heat demand reduction by more than $18 \%$ due to fuel substitution. The woodstove-related health costs have only marginal (0.3\%) effect on heat savings. The heat from woodstoves is replaced by increased generation in the respective primary technologies. In the 2030 scenario REINVEST, where consumers are forced to reinvest in the existing technology type, heat savings reach almost a quarter of initial heat demand. Here the variable heating costs are higher than in 2011 due to higher fuel costs and heat savings can reduce the variable share of investment expenditures by downsizing heating capacity. Health costs related to woodstove use decrease due to better fuel efficiency of woodstoves and lower particle pollution. As a consequence of this health costs have no effect on the amount of heat generation by woodstoves. When consumers have a free choice of technology in the 2030 scenarios (INVEST_REF and INVEST), wood pellet boiler is the most attractive technology due to low fuel cost, compared to other fuels. Due to low variable heating costs of wood pellet boilers only $8 \%$ of heat demand is reduced by heat savings.

Fuel consumption decreases when less heat is produced in woodstoves in the externality cases (Figure 6 to the right). Clearly heat savings also lead to decreased energy resource use. Due to higher fuel efficiency of 2030 technologies fuel consumption is also lower in 2030. The INVEST scenario has also been calculated with socioeconomic cost characteristics, i.e. investments do not include VAT and fuel costs do not include taxes and levies, but the expected $\mathrm{CO}_{2}$ cost in 2030. The optimal solution includes $13 \%$ of heat savings. As much as 80 percent of heat is generated in electricity based technologies - air-water heat pumps (76\%) and electric heating (4\%). Natural gas boilers cover the rest - around $20 \%$ of heat demand - in the areas currently supplied with natural gas.

In the 2030 scenarios fuel taxes and levies are increased proportionally to basic fuel prices, which results in high electricity prices when compared to wood pellet prices. A sensitivity analysis of the INVEST scenario has been made with taxes and levies only increasing with inflation. As a result the electricity price is 33\% lower but the wood pellet price is only $1 \%$ lower. The optimal solution still favours wood pellet boilers. Heat savings do not change in this sensitivity analysis and reaches $8 \%$ of the initial heat demand. 
Figure 7 and Figure 8 analyse implementation of heat savings in more detail. When considering individual heating technology mix of today, window replacement and insulation of floor and roof are most cost efficient both in 2011 and 2030 scenarios. From Figure 5 it can be seen that ventilation with heat recuperation and insulation of walls become cost efficient in 2030. When woodstove use related health costs are included in the REINVEST_EXT case secondary heat generation in combination with electric heating becomes more expensive and wall insulation becomes cost efficient for these consumers. Whereas inclusion of health costs in 2011 scenarios have no effect on the choice of heat saving measures. When consumers freely choose wood pellet boilers, the only economically viable heat saving measure is windows. It is also almost the only cost efficient measure for rented single family houses. Mechanical ventilation with heat recovery, floor and wall insulation are only implemented in owner-occupied dwellings.
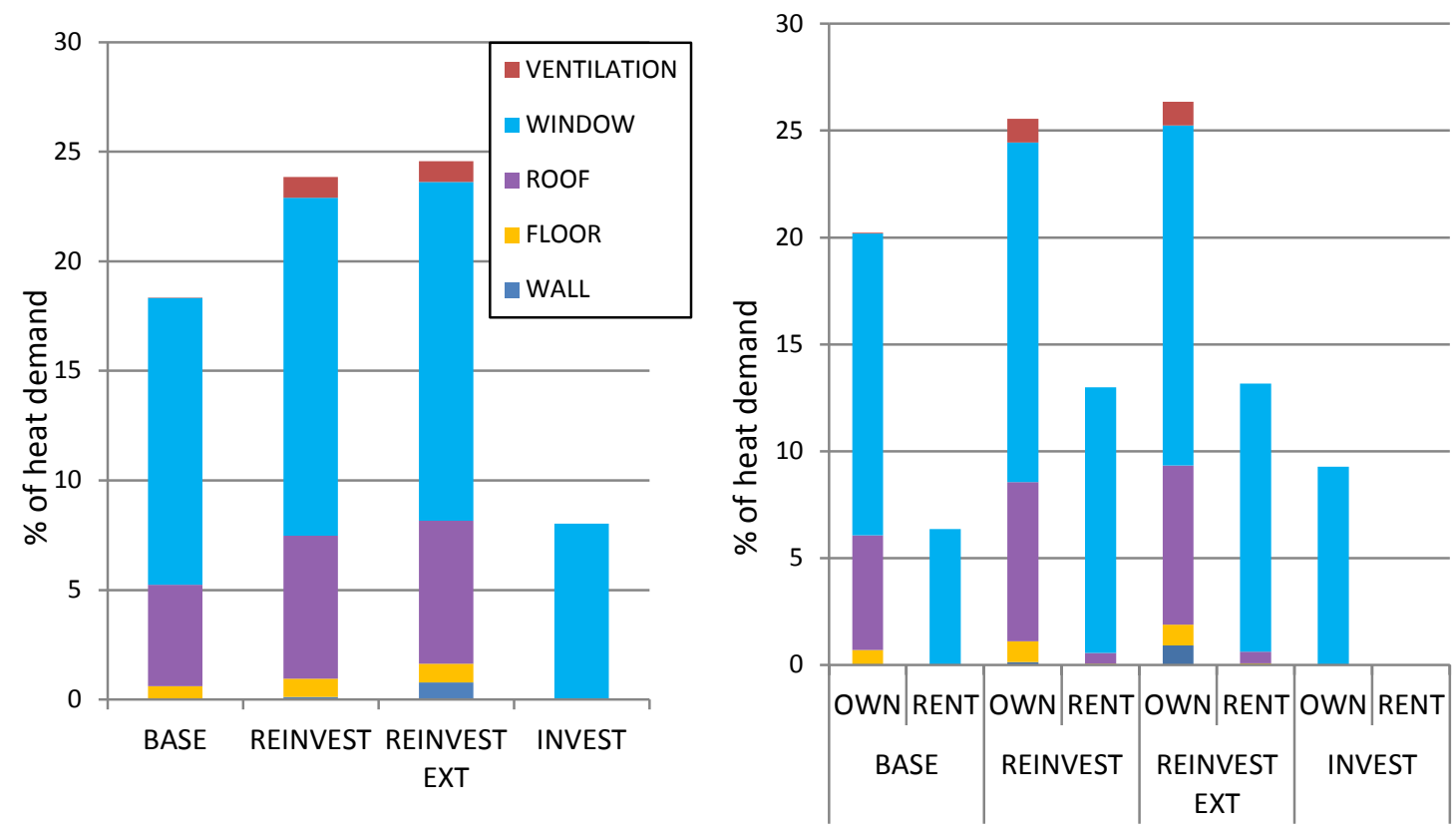

Figure 7 Total implemented heat savings,\% of initial heat demand (to the left); and Heat savings in owner occupied and rented buildings, expressed in\% of initial heat demand in each group (to the right)

Heat savings are least economically viable when heat is generated in wood pellet boilers (Figure 8). The largest share of heat savings is cost efficient for consumers with oil boilers and electric heating, both in 2011 and in 2030. Even though electric heating is more costly than oil, heat savings reduce a higher share of heat demand in houses with oil boilers in the optimal situation in 2011. The reasons are: a higher share of buildings with electric heating has woodstove as secondary heating source, which reduce heating cost; and houses with oil boilers have a higher heat saving potential at lower cost. Included health costs do not contribute much to the savings volume except for buildings with electric heating. 


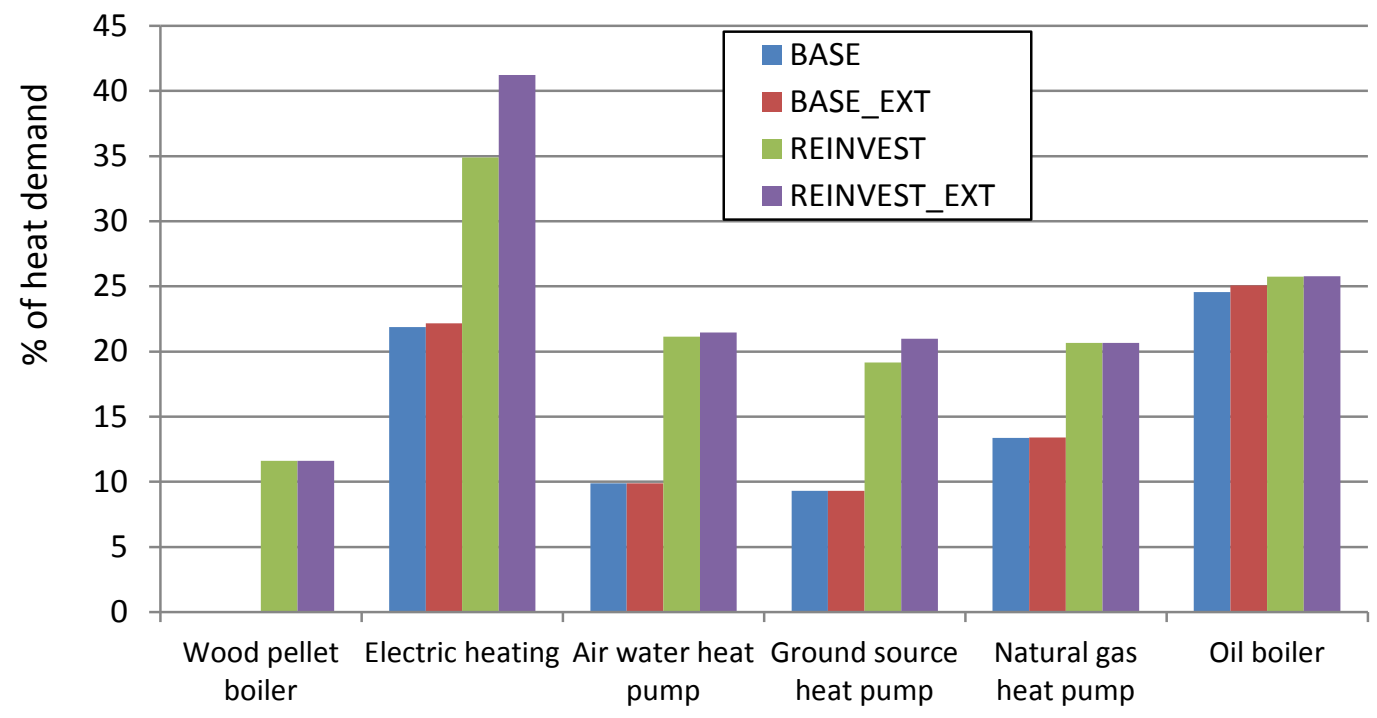

Figure 8 Heat savings in different consumer groups by existing heat generation technology - in 2011 and 2030 scenarios, where consumers have no freedom to choose a technology, in\% of heat demand in each group

Even though the private optimisation results show that the preferable technology is wood pellet boiler, it is not likely that all private consumers would shift to this technology in the real world situation. The described calculations do not include individual preferences of the consumers, nor do they include the issue of available space, needed for different technologies. Therefore, a larger actual variation in the choice of new individual technologies is expected than indicated by the results of the optimisation.

\section{Rebound effects}

A general effect to consider when modelling energy savings is the rebound effect. By increasing energy efficiency for example by increasing insulation standard of a house the variable costs of providing an energy service decrease. Therefore a consumer responding to lower costs will, depending on the price elasticity of heating, demand a higher level of comfort. That corresponds to increasing the room temperature, the heated area, the share of a year that an area is heated or even increasing hot water consumption.

Energy savings reduce the variable costs of providing heating comfort and therefore the short term price of heating. The model implementation is made by initially running the optimisation model without the flexible investment options and then comparing this to an optimal solution including the flexibility for heat technology or savings. The change in variable heating costs $\Delta V C_{C G}$ (fuel and health costs due to pollution) between the two scenarios is then treated as a cost change that affect heat demand. Finally we feed this demand reaction to an effect on total energy input needed to supply heat demand. The rebound calculation thus capture the demand effect of reduced variable cost without including this effect in the optimisation.

$$
D H_{C G}^{\text {Rebound }}=\left(D H_{C G}-H S_{C G}\right) \cdot\left(1+\frac{\Delta V C_{C G}}{V C_{C G \text { before }}} \cdot e_{G C}\right)
$$

The elasticity: $e_{C G}$ for each category of consumers is assumed identical. As the optimal savings investment and thereby change in variable costs is differing greatly among categories the rebound effect will also exhibit large variation. This approach is limiting the demand reaction to a price response and omitting income effects as this is not incorporating macroeconomic effects as, for example, in Giraudet et. al. (2012). 


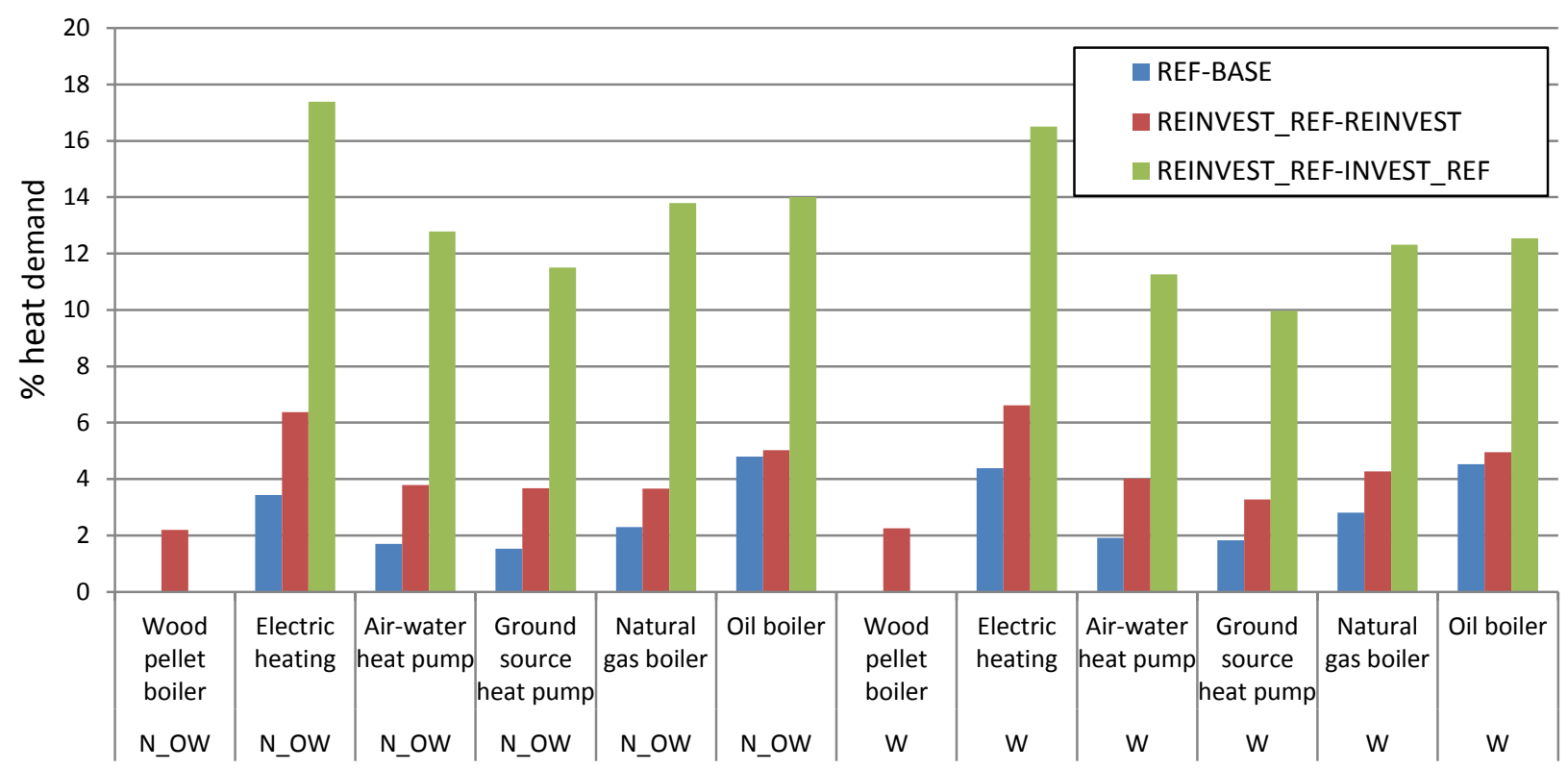

Figure 9 Rebound effect as percentage of heat demand after savings or as an increase in heat consumption after switch to another heat generation technology

The results of the optimisation have shown that cost efficient levels of heat savings for different scenarios and cases as well as for consumers using different heating technologies and having different ownership status vary from $8 \%$ to more than $40 \%$. This section illustrates the rebound effect when the variable cost for covering a building's heat demand is reduced due to implemented heat saving measures or switch of heating technology.

Figure 9 illustrates the importance of accounting for the rebound effect as heat savings or shift to cheaper heating technology reduce heating costs that result in a rebound effect driving heat consumption up again. The three rebound cases illustrated are:

1. REF-BASE: comparing heating expenditures in 2011 scenario without heat savings (REF) and with heat savings (BASE)

2. REINVEST_REF-REINVEST: comparing heating expenditures in 2030 scenario without heat savings (REINVEST_REF) and with heat savings (REINVEST)

3. REINVEST_REF-INVEST_REF: comparing heating expenditures in 2030 scenario with existing technology mix (REINVEST_REF) and when consumers freely choose a technology - in this case to wood pellet boilers (INVEST_REF)

The two first cases represent the rebound in percentage of the heat demand after initial savings have been implemented. The third case represents the increase in heat demand when variable heating costs are reduced as a result of free choice of cheaper technology - woods pellet boiler. N_OW represent no wood stove and W represents dwellings with woodstove. The rebound is the least for the scenarios with low fuel prices (2011 scenarios) but varies depending on existing heating technology and heating costs per $\mathrm{m}^{2}$ as well as heat savings. Fuel costs are highest for electric heating, however houses with oil boilers have higher heat saving potential and more savings are implemented here. As a result variable heating costs decrease most for consumers using oil for heating (Appendix A). The cost reduction results in the largest rebound for oil boilers (5\% in Figure 9) compared with other technologies. Consumers with wood pellet boilers do not invest in savings and therefore no rebound is observed.

In 2030 more heat savings are implemented and the rebound effect in Figure 9 is higher for these scenarios. Electricity price increases significantly and considerable heat savings are implemented in buildings with electric heating, leading to the largest rebound effect (6.5\%) among all technology groups in this scenario.

Comparing the three rebound cases we find that largest cost reductions for heating are achieved when the consumers have a free technology choice, where all switch to wood pellet boilers. Depending on their previous 
technology, cost reductions are the largest for electric heating and these dwellings/households exhibit the largest rebound. The buildings with woodstoves have lower initial heating costs, which leads to smaller cost reduction and thereby less rebound effect.

Figure 10 illustrates the difference between the rebound effects in houses built before and after 1979, the year when significantly more strict energy efficiency requirements were introduced in building codes in Denmark. Heat demand in case REINVEST_REF-INVEST, with no heat savings but replacement of technologies with wood pellet boilers, increases slightly more in the newer buildings, than in older buildings. The reason is that newer buildings have a lower share of secondary heating before switching to wood pellet boilers than older buildings, which results in higher heating costs and a larger change in variable costs and subsequent rebound effect.

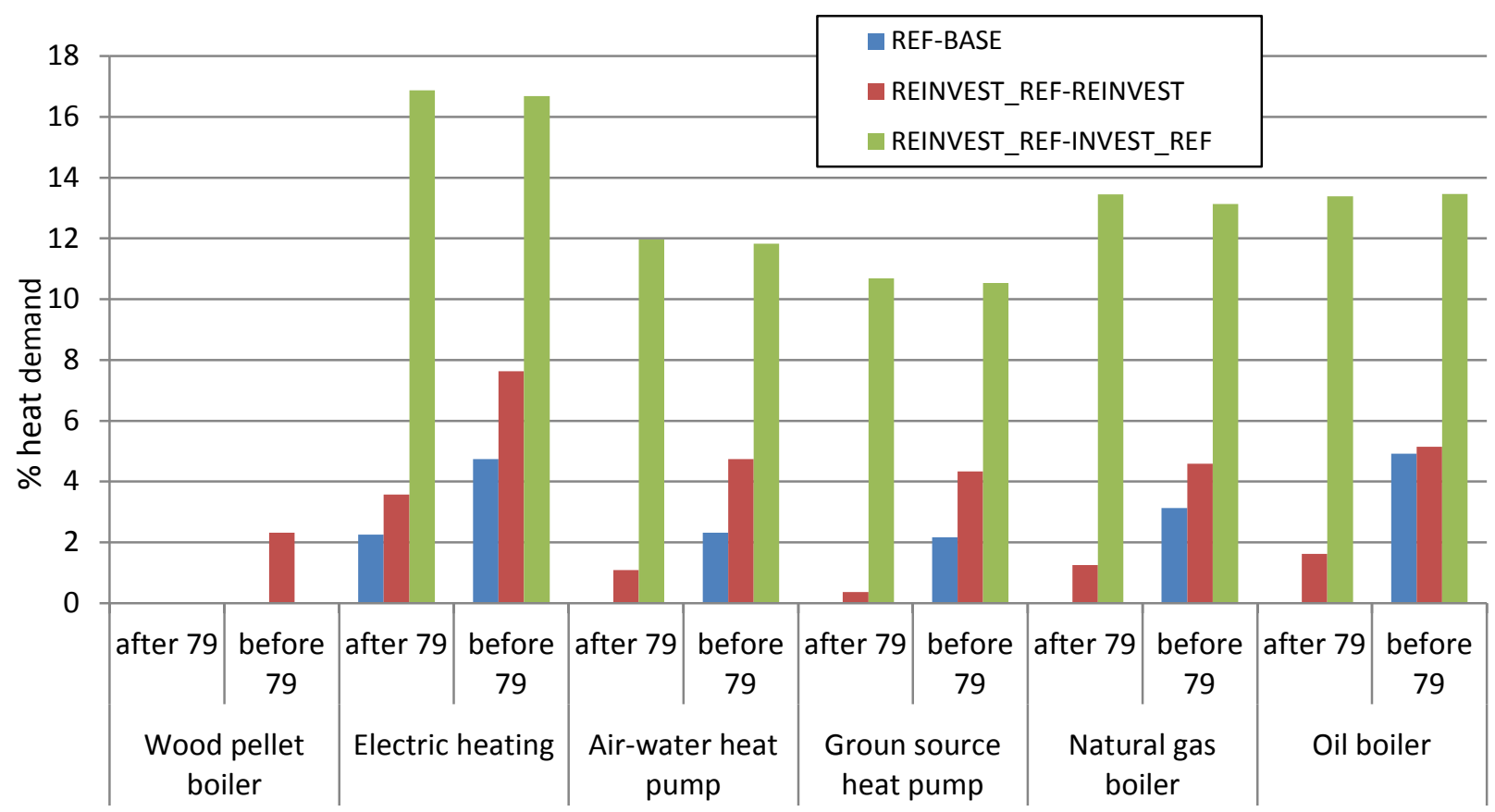

Figure 10 Rebound effect as percentage of heat demand after savings by primary heating technology and building age

In (Appendix A) the rebound is represented as the negative contribution to savings. Net savings (original savings reduced by the rebound) are then the positive columns. First of all the higher fuel prices in 2030 in the REINVEST case result in larger savings as already observed in Figure 7 and Figure 8. Both the heat savings and rebound effect vary depending on especially building age but also the heating technology. In 2011 (REF-BASE case) only new buildings that are equipped with electric heating implement heat savings, while older buildings with all types of heating utilise heat saving potential to a varying degree.

The rebound effect is varying quite substantial between the categories of single family houses (last two columns, Table 6). Heat consumption increases again between 3\% and 14\% after heat savings have been implemented, the average for all building categories being 3.4\% and 4.5\%, depending on the consumer type and the scenario. This is a result of the combination of fuel costs, heat saving potential and use of secondary heating technology, but fuel cost is the dominating factor. Heat demand increases most (by $12.6 \%$ on average) when consumers are no longer locked in to today's technology and choose the cheapest - wood pellet boilers. 
Table 6 Rebound effect in different scenarios - summary

\begin{tabular}{|l|c|c|c|c|c|c|}
\hline & $\begin{array}{c}\text { Heat } \\
\text { Scenario }\end{array}$ & $\begin{array}{c}\text { Average } \\
\text { decrease in } \\
\text { savings,\% } \\
\text { heat demand }\end{array}$ & $\begin{array}{c}\text { Average } \\
\text { cost per m2,\% }\end{array}$ & $\begin{array}{c}\text { Average rebound } \\
\text { rebound,\% of } \\
\text { heat demand }\end{array}$ & $\begin{array}{c}\text { Rebound,\% of heat demand } \\
\text { effect,\% of heat } \\
\text { savings }\end{array}$ & $\begin{array}{c}\text { Rerter savings } \\
\text { min }\end{array}$ \\
\hline REF-BASE & 18.3 & 19.8 & 3.4 & 14.9 & 2.6 \\
\hline $\begin{array}{l}\text { REINVEST_REF- } \\
\text { REINVEST }\end{array}$ & 23.8 & 25.7 & 4.5 & 14.3 & 10.2 \\
\hline $\begin{array}{l}\text { REINVEST_REF- } \\
\text { INVEST_REF }\end{array}$ & - & 68.9 & 12.6 & - & 2.6 & 13.8 \\
\hline
\end{tabular}

A main observation is that the households living in buildings with poor energy efficiency and high heat saving potential also have high heat generation costs due to high fuel costs and low fuel efficiency of a technology. As a result they have more incentives to save energy and/or to shift to a cheaper technology, which implies large variable heating cost reductions and therefore also a relatively large rebound.

For all heat savings of $18.3 \%$ and $23.8 \%$ in the two savings scenarios only $3.4 \%$ and $4.5 \%$ are "lost" again as a consequence of the rebound. The rebound effect in total is thus found to be of less importance than the direct elasticity of demand would suggest and the conclusion is that rebound effects are far from evading the initially achieved heat savings.

\section{CONCLUSIONS}

The results of this study reveal important linkages between investment behaviour in energy savings and heat technology choice for the residential heating sector. A homeowner has control of both decisions and should furthermore include emissions that affect his own health in the optimisation.

Optimal heat saving investments are affected considerably by existing heating technology resulting in much higher savings in houses with oil boiler (24\%) compared to houses with wood pellet boilers that implement no savings at all. The average optimal savings are $18 \%$ in our BASE case with 2011 prices. When the flexibility to invest in a new heating source is introduced for 2030 the optimal savings drops from 24\% (REINVEST) to 8\% (INVEST), because there is a nearly complete shift to the cheapest technology - in this case wood pellet boilers. This indicates that incorporating technology flexibility/uncertainty will reduce the optimal level of heat saving investment. Our model shows the significance of choosing heat saving investments and heat generation technology simultaneously when a building undergoes general renovation. In this light, optimisation with existing technologies could lead to overinvestment in heat savings, from a private point of view. Such optimal inclusion of future technology switch contributes to explaining the gap between identified optimal heat saving investments with existing heat technology and observed real world behaviour with a much lower level of investments.

Including health costs due to woodstove use does influence the extent of using this secondary heating technology, which decreases 4 times in the 2011 case (Figure 6, left). This reduces health damage and also slightly reduces fuel consumption since primary heating technologies have higher efficiencies. Including health costs have only marginal effect on the extent of savings $(+0.3 \%)$ and choice of primary heating technology. We can conclude that if private consumers include the damage to their own health in their optimisation they would use and install much less wood stoves, but would not change other heating decisions.

The difference in behaviour between renters and owners are reflected in much less savings investments for renters (in BASE case 6\% compared to 20\% Figure 7), which results in higher (variable) costs for covering demand for thermal comfort in this consumer group. It is only interesting for renters to invest in new windows, where appropriate long term optimisation by owners would include roof and floor insulation. Barriers for renters thus result in inefficient low levels of savings investment compared to a socioeconomic criterion.

Comparing to the total technical options for heating energy savings, included in the calculations (56\%) our results indicate that almost half of this potential (nearly 25\%) would be privately optimal to implement up to 2030 based on the projected fuel price increase and unchanged composition of heating technologies. 
The rebound effect has attracted quite a lot of attention in discussing efficiency of heat savings measures. Variable cost changes cause a rebound and in our scenarios heating costs are reduced between $20 \%$ and $70 \%$ on average for all consumer groups. We find the rebound effect varies considerably between consumer groups, but the overall effect is found to be relatively small. With initial heat savings of around $20 \%$ the rebound increases consumption by approximately $3 \%$ again. This is not enough to question the use of energy savings policies and incentives, but $3 \%$ of total energy demand for heating should still be considered in demand projections and projecting effects of energy saving policy initiatives.

Another very important result is the great difference between the results of socioeconomic optimisation and private optimisation of individual heating. The optimal mix of energy sources are quite different in the free investment choice (INVEST scenario case). Consumers use mainly wood pellets as a result of private consumer optimisation, whereas socioeconomic optimisation favours heat pumps to a much larger extent. Such socioeconomic optimisation results are in line with the results of other socioeconomic energy system analysis such as optimisation of the future Danish heat and power sector (Karlsson et al., 2011 and Zvingilaite and Balyk, 2012). Thus our results show that existing fuel tax structures in Denmark do not favour technologies, which are optimal in the future energy sector from a socioeconomic point of view. When phasing out fossil fuel technologies and moving towards renewable energy supply, new public regulations and tax structures are important in order to ensure implementation of the socioeconomic optimal development.

The results are dependent on both the specifics of Danish heating sector and the projected price developments for fuels and technologies and must be treated carefully when comparing to other countries or time horizons.

\section{ACKNOWLEDGEMENTS}

The presented study is part of the research in Centre for Energy, Environment and Health, financed by The Danish Strategic Research Program on Sustainable Energy under contract no 2104-06-0027.

\section{REFERENCES}

Amstalden R. W., Kost M., Nathani C., Imboden D. M., 2007. Economic potential of energy-efficient retrofitting in the Swiss residential building sector: The effects of policy instruments and energy price expectation. Energy Policy, 35, 1819-1829.

Banfi S., Farsi M., Filippini M., Jacob M., 2008. Willingness to pay for energy-saving measures in residential buildings. Energy Economics, 30, 503-516.

Brandt et al., CEEH Scientific Report No 3: Assessment of Health Cost Externalities of Air Pollution at the National Level using the EVA Model System, Centre for Energy, Environment and Health, Roskilde.

Clinch J. P., Healy J. D., 2001. Cots-benefit analysis of domestic energy efficiency. Energy Policy, 29, 113-124.

DEA, 2011. Energy Statistics 2009. Danish Energy Agency. www.ens.dk, accessed February $1^{\text {st }} 2011$.

Danish Energy Agency, 2011. Forudsætninger for samfundsøkonomiske analyser (Recommendations for assumptions in socioeconomic studies of energy sector; in Danish). Copenhagen, April 2011.

DERA, 2011. Natural gas and electricity prices. Danish Energy Regulatory Authority, www.energitilsynet.dk, accessed August $11^{\text {th }} 2011$.

Danish Ecological Council, 2012. Akut behov for afgift på brændeovne (Urgent need for woodstove taxes; in Danish), www. Ecocouncil.dk, accessed April $19^{\text {th }} 2012$.

Dong Energy homepage, 2012. www.dongenergy.dk, accessed April 19 2012.

European Commission, 2011. Database on Energy Saving Potentials, www.eepotential.eu, accessed Feb. 2011.

Evald A., 2010. Brændeforbrug i Danmark 2009 (Wood consumption in Denmark; in Danish). Force Technology. EOF, 2011. Oil prices. Danish Oil Industry Association, www.eof.dk, accessed August $11^{\text {th }} 2011$.

Gaterell M. R., McEvoy M. E., 2005. The impact of energy externalities on the cost effectiveness of energy efficiency measures applied to dwellings. Energy and Buildings, 37, 1017-1027.

Giraudet L. G., Guivarch C., Quirion P., 2012 Exploring the potential for energy conservation in French households through hybrid modelling. Energy Economics 34 (2), p. 426-445. 
Grønvald, 2007. Her er de 10 bedste brændeovne (Her are the 10 best woodstoves; in Danish), http://fpn.dk/bolig/article1050462.ece, accessed April 19 2012.

IPCC, 2007. Climate Change 2007: Mitigation of Climate Change. Contribution of working group III to the fourth assessment report of the Intergovernmental Panel on Climate Change, Metz B., Davidson O. R., Bosch P. R., Dave R., Meyer L. A. (eds), Cambridge University Press, Cambridge, United Kingdom and New York, NY, USA. Jakob M., 2006. Marginal costs and co-benefits of energy efficiency investments. The case of the Swiss residential sector. Energy Policy, 34, 172-187.

Karlsson K. B., Balyk O., Zvingilaite E., Hedegaard K., 2011. District heating versus individual heating in a $100 \%$ renewable energy system by 2050. Presented at 6th Dubrovnik Conference on Sustainable Development of Energy Water and Environment Systems, Dubrovnik, Croatia, 25-29 September 2011.

Klinge Jacobsen, H., 2000 Technology diffusion in energy-economy models: The case of Danish vintage models, The Energy Journal, 21 (1), p. 43-71

Kragh J., Wittchen K. B., 2010. Danske bygningers energibehov i 2050 (Energy demand of the Danish buildings in 2050; in Danish). Aalborg university, 2010.

Lund H., Möller B., Mathiesen B.V., Dyrelund A., 2010. The role of district heating in future renewable energy systems, Energy 35, 1381-1390.

Mathiesen B. V., Lund H., Connolly D., 2011. Heating technologies for limiting biomass consumption in 100\% renewable energy systems. Presented at 6th Dubrovnik Conference on Sustainable Development of Energy Water and Environment Systems, Dubrovnik, Croatia, 25-29 September 2011.

Möller B., 2008. A heat atlas for demand and supply management in Denmark, Management of Environmental Quality: An International Journal 19, 467-479.

Nielsen O. K. et al., 2010. Annual Danish informative inventory report to UNECE. Emission inventories from the base year of the protocols to year 2008. National Environmental Research Institute, Aarhus University.

ODYSSEE, 2009. Energy efficiency trends by sectors in Europe. Households, updated December, 2009. www.odyssee-indicators.org, accessed December $1^{\text {st }} 2010$.

Olesen H. R., Wåhlin P., Illerup J. B., 2010. Brændefyrings bidrag til luftforurening (Contribution of wood combustion to air pollution; in Danish). Danmarks Miljøundersøgelser (National Environmental Research Institute), Aarhus University.

Petersen L. K., 2008. Autonomy and proximity in household heating practices: the case of wood-burning stoves. Journal of Environmental Policy and Planning, 10:4, 423-438.

Pope C. A. III, Dockery D. W., 2006. Health effects of fine particulate air pollution: lines that connect. J. Air \& Waste Manage. Assoc., 56, 709-742.

Rambøll Danmark, 2008. Varmeplan Danmark, Bilagsrapport (Heat Plan Denmark, Appendix report; in Danish), Dansk Fjernvarme (The Danish District Heating Association), Virum.

Siller T., Kost M., Imboden D., 2007. Long-term energy savings and greenhouse gas emission reductions in the Swiss residential sector. Energy Policy, 35, 529-539.

Sønderskovhjemmet, 2011. Wood prices, www.sønderskovhjemmet.dk, accessed August $11^{\text {th }} 2011$.

Sydjyskstoker, 2011. Wood pellet prices, www.sydjyskstoker.dk, accessed August $11^{\text {th }} 2011$.

Tommerup H. (Ed), 2010. Energirenoveringstiltag - katalog (Catalogue of energy saving measures; in Danish), Technical University of Denmark.

Tommerup H., Svendsen S., 2006. Energy savings in Danish residential building stock. Energy and Buildings, 38, 618-626.

Wittchen K. B., 2004. Vurdering af potentialet for varmebesparelser i eksisterende boliger (Assessment of the heat saving potential in the existing dwellings; in Danish), Aalborg University, Hørsholm.

WOODUSE project homepage, 2009. wooduse.dmu.dk accessed April $19^{\text {th }} 2012$.

Zvingilaite E., Balyk O., 2012. Modelling of heat supply and heat savings in a $100 \%$ renewable heat and power system in Denmark, draft paper. 
Appendix A

Table Al Change in variable heating costs in the analysed rebound cases

\begin{tabular}{|c|c|c|c|c|}
\hline & $\begin{array}{l}\text { REF-BASE } \\
\text { Variable cost change, } \%\end{array}$ & $\begin{array}{r}\text { REINVEST_REF-REINVEST } \\
\text { Variable cost change, } \%\end{array}$ & $\begin{array}{c}\text { REINVEST_REF-INVEST_REF } \\
\text { Variable cost change, } \%\end{array}$ \\
\hline N_OW & Wood pellet boiler & 0 & 11 & 0 \\
\hline N_OW & Electric heating & 19 & 35 & 87 \\
\hline N_OW & Air-water heat pump & 9 & 20 & 64 \\
\hline N_OW & Oil boiler & 25 & 26 & 70 \\
\hline $\mathbf{w}$ & Wood pellet boiler & 0 & 12 & 0 \\
\hline $\mathbf{w}$ & Electric heating & 23 & 35 & 83 \\
\hline $\mathbf{w}$ & Air-water heat pump & 10 & 22 & 56 \\
\hline w & Oil boiler & 24 & 26 & 63 \\
\hline
\end{tabular}

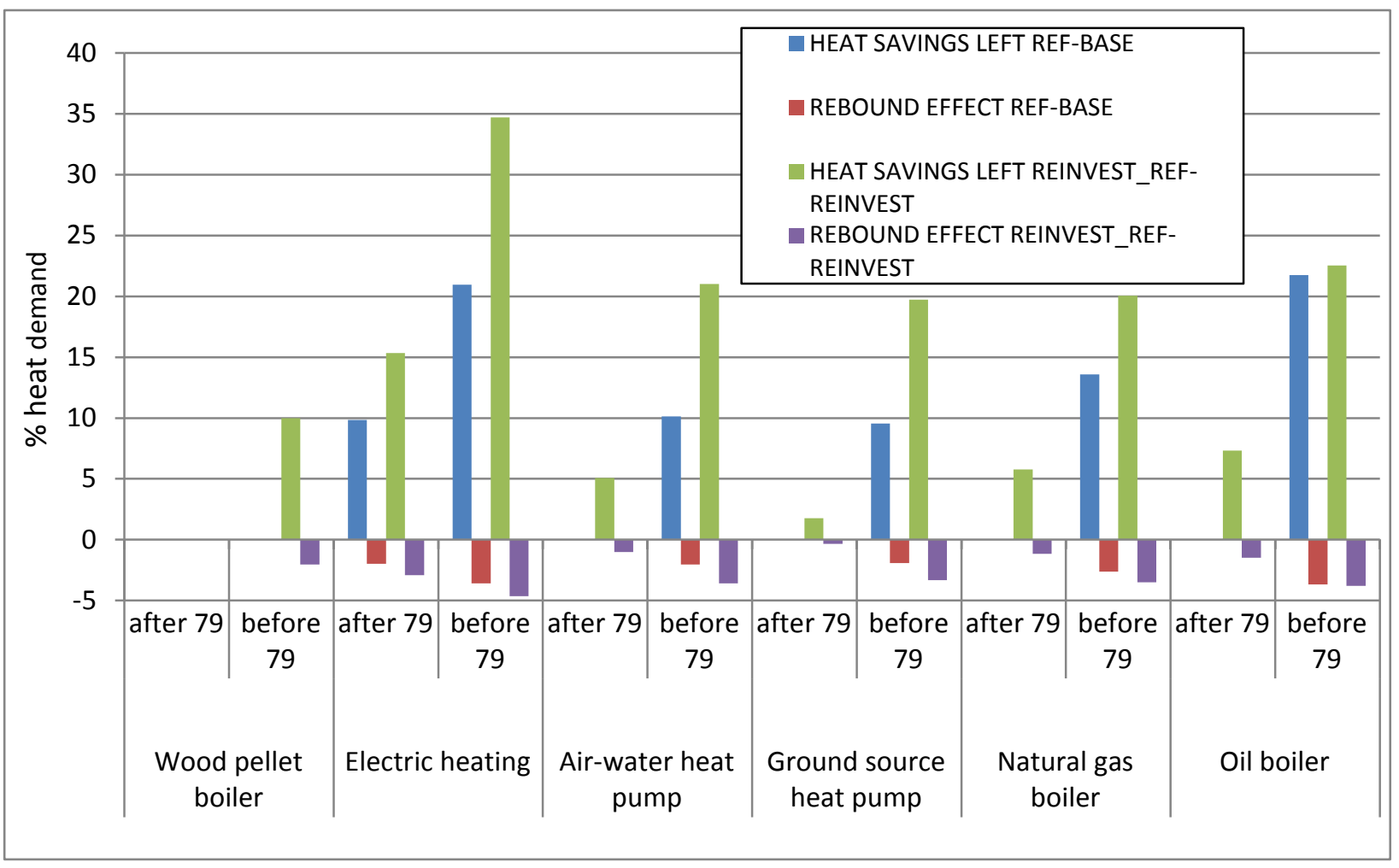

Figure A.1 Heat savings after rebound effect has been accounted for, by primary heating technology and building age 